\title{
Iranian centers of excellence in medical sciences: A qualitative study to analyze the current state and design of a future roadmap
}

\author{
Behzad Damari ${ }^{1}$, Seyed Kamran Kamrava ${ }^{2}$, Siamak Kazemi-asl ${ }^{3}$, Narges Rostamigooran ${ }^{* 4}$ (D) \\ Received: 4 Feb 2018 \\ Published: 26 Oct 2020
}

\section{Abstract}

Background: Due to the law for the fifth development plan and Iran's 20- year economic perspective, Centers of Excellence (COEs) were expected to upgrade the level of research and education besides improving infrastructures in Iran. This study is aimed to analyze the current state of national centers of excellence and designing a future roadmap.

Methods: In this qualitative study, data was gathered by reviewing relevant national \& international literature and upstream documents, interview with experts, and focused group discussions with stakeholders. Finally, a roadmap was prepared for approval.

Results: Lack of common understanding of the COEs definition, lack of clear professional orientation for each center, lack of mandate and commitment in using COEs in the health system and community health promotion, weakness in enticing elites, and unresponsive to basic needs of the country were five major challenges COEs encountered.

The consensus prospective vision for centers of excellence was developed based on the establishment and management of special institutions of thought and technology in centers of excellence to advise health policymakers and provide the highest level of the regional and global position.

Conclusion: Despite over a decade of development of medical COEs, their goals have not been reached yet. Enactment of designed roadmap and its subprojects in the Supreme Council of Centers is the primary steps for functional improvement of COEs.

Keywords: Centers of excellence, Roadmap, Qualitative Study

Conflicts of Interest: None declared

Funding: This study was supported in part by the Educational Development Center of Health and Medical Education Ministry.

\section{*This work has been published under CC BY-NC-SA 1.0 license.}

Copyright $\odot$ Iran University of Medical Sciences

Cite this article as: Damari B, Kamrava SK, Kazemi-asl S, Rostamigooran N. Iranian centers of excellence in medical sciences: A qualitative study to analyze the current state and design of a future roadmap. Med J Islam Repub Iran. 2020 (26 Oct);34:143. https://doi.org/10.47176/mjiri.34.143

\section{Introduction}

Centers for scientific excellence are the major drivers of development in the twenty-first century. These centers are in interaction with Think Tank (idea-generating institutions). Centers of Excellence (COEs) in comparison with their predecessors, traditional research institutions, share some characteristics in traditional methods, at the same time, are distinguished by some special features (1). Flexible organizational structure and democratic relationships, interdisciplinary and multidisciplinary and independent (both at the same time) activities, industry and economy

Corresponding author: Dr Narges Rostamigooran, rostamigooran@gmail.com n.rostami@behdasht.gov.ir

\footnotetext{
1. Governance and Health Department, Neuroscience Institue, Tehran University of Medical Sciences, Tehran, Iran

2. Head and Neck Research Center, Hazrat Rasoul Akram Hospital, Tehran University of Medical Sciences, Tehran, Iran

3. Rajaie Cardiovascular Medical and Research Center, Iran University of Medical Sciences, Tehran, Iran

4. Ministry of Health and Medical Education, Tehran, Iran
}

connections, elite human resources training and development, developing social capital, creativity and innovation, effective international communication, public and private sector support, and quality control are some distinguishing characteristics of COEs (1-4). Some definitions of the Center of Excellence are available in Box 1.

Changing the approach of universities and educational centers toward the consumers' needs and quality of life necessities caused the number and diversity of scientific centers to increase (1-5) .COEs are trying to respond to these

$\uparrow$ What is "already known" in this topic:

Centers of Excellence as a superior organization which can provide product or special services in specific areas of technology, business or public issues are the major drivers of development in the twenty first century.

$\rightarrow$ What this article adds:

By understanding the Centers of Excellence challenges, recommend a roadmap for policy and decision makers. 
Box1. Definition of Centers of Excellence (COEs)

1. Structure in which developme1. Structure in which development of research and technology runs according to the global standard by measurable scientific output including Learning and innovation in technology (2).

2. A group which cooperate on a specific domain and uses of best practices to achieve results. This team can include part-time or full-time members (3).

3. The center of excellence is a superior organization which can provide product or special services in specific areas of technology, business or public issues. These services are consistent with organization's unique needs and competences of centers of excellence (4).

4. The center of excellence is a superior organization which gets highest attainable standards in their specific areas by the synergies created through combination and integration of efficient and effective performance (1).

nt of research and technology runs according to The global standard by measurable scientific output including Learning and innovation in technology (2).

2. A group which cooperate on a specific domain and uses of best practices to achieve results. This team can include part-time or full-time members (3).

3. The center of excellence is a superior organization which can provide product or special services in specific areas of technology, business or public issues. These services are consistent with organization's unique needs and competences of centers of excellence (4).

4. The center of excellence is a superior organization which gets highest attainable standards in their specific areas by the synergies created through combination and integration of efficient and effective performance (1).

basic demands of societies through four main conceptual factors including; innovation, competition, quality, and technical knowledge.

Development patterns of COEs are different throughout the world (6). State models are established in some countries like the United States (in state's universities) and in the field of government's role in Japan, Malaysia and Korea. In the Non-state model, institutions and companies compete with universities by establishing superior scientific centers. In the pattern of international and multinational companies, COEs are established in order to develop Innovation and access to global markets which is followed by Western Europe, The United States of America and Japan

Centers of excellence are classified based on their origin as Educational centers which relates national or international Association of Education, research institution and a third party (supplier and resource utilization) to each other (7); Clinical or health care centers which provide quality standards for healthcare and national services and collaboration between the patient and the healthcare provider, (8) and Research COEs, which usually are educational or are related to clinical services, but research activities are dominant on them (9).

Research centers have been appeared in the academic era in Iran from two decades ago when the country needed to applied research for development more than before and regulation of governing bodies in science and research was revised. Paragraph six of law enforcement strategies for the economic, social and cultural development of the Islamic
Republic of Iran is (1379-1383) as follows; "some universities and educational institutions and scientific research centers should promote to excellence centers working on various fields of forecasting, financial, technical and legal science". According to academic regulations, centers of excellence contain a group of actual or virtual outstanding faculty and staff with distinctive capabilities in the context of a specialized branch of medical science and related fields that are working in one or more areas of science, research, education and health care treatment services. The main characteristics of COEs are innovation and superior academic achievement at national, regional or international domain, to meet the basic needs of the country $(10,11)$. Goals and tasks of the COEs are defined as Box 2 (10).

Despite the fact that all COEs have had significant activities in Iran, there are no implement's reports available since the establishment of these centers, and the overall performance has not been assessed in line with the law. Moreover, there is not still any accurate plan to move according to the program of 20-years vision of the country. Analysis of the current status of COEs with the participation of all stakeholders can help to fulfill the following objectives. So, the main focus of this research is to study the actual status of these centers throughout the country then, suggest a future roadmap.

\section{Methods}

This is a descriptive-analytical study that has applied a combination of strategies to gather data and content analysis methodology. These strategies contain library-archives research, interview with informed experts and focus group

Box 2. Goals and tasks of Iran centers of excellence according to the Constitution, ratified in 2000

1. Access to the latest scientific findings and increased participation in knowledge frontiers extension and promote scientific position.

2. Educate the top researchers and scholars.

3. Making dynamic and capable environments.

4. Making effective international communication.

5. Invite sophisticated Iranian faculty and researchers residing inside or outside of the country.

6. Doing necessary researches to cover basic problems of country.

7. Opening up New field in high-level scientific requirements. 
discussions with stakeholders.

\section{Library and Archives research}

Data regarding centers of excellence definitions, history of these institutions in Iran and throughout the world, comparing their goals, dimensions of COEs and examples of these centers and experiences of other countries, gathered from review and analysis of relevant documents to center of excellence since establishment. Upstream documents reviewed are in Box 3.

Some documents which collected and have been analyzed are:

- Iranian Council Regulations of Centers and their List.

- Results of the First Evaluation of Centers Performance.

- List of projects which were funded and implemented.

- Report of centers of excellence meetings.

- A comparative assessment of centers of excellence in Iran with global counterparts.

- New programs for medical centers of excellence.

- Report of the centers of excellence performance. In addition, research databases such as Google Scholar and validated internal and external ones (such as Irandoc, Elsevier, Scopus, Pubmed) and relevant valid sites such as the WHO were reviewed, articles, and documents were gathered and reviewed. A draft of the future roadmap of Centers of scientific excellence, interventions and operational plans of other countries were reviewed. The draft was reformed in the focus group discussion sessions.

\section{Interview}

The other strategy of data collection was conducted through a structured interview. The questionnaire was designed in two parts; closed questions for demographic data and open questions to achieve the researchers' viewpoint regarding the different dimensions of the management of scientific COEs in Iran's health sector as well as the factors causing the situation. The sampling method was intentional and purposeful. Twenty-four stakeholders and experts in the field of role and dimensions of scientific COEs and policymaking in human resources in the health sector were chosen and informed by an email about the purposes of the study, 18 of them consented to participate in the study. Entry criteria for experts were doing at least two studies in the related field.

The interviewer was a community medicine specialist (MD-MPH) .At the time of research, she was a part-time researcher at the National Institute for Health Research and according to her education, she was interested in the subject and accepted to participate as interviewer. She performed around one-hour interviews, with 18 participants; 15 men and 3 women, who all are MD or Ph.D. in health policy.

The validity of the questionnaire was confirmed by experts. Official correspondence was conducted for the appointment of the interview. The interviewer recorded the interviews after getting permission. Ideas of stakeholders and experts were collected through questionnaires and interviews and field notes during interviews on four questions then came to the conclusions by analyzing data and characterizing the main themes:

- In your opinion, what are the main problems of COEs?

- What incentive strategies do you recommend?

- What educational strategies do you recommend to empower COEs?

- What fields / professional fields do your center choose to work on (this question is for leaders)?

None of the interviews were repeated.

\section{Focused group discussion}

In this regards, Members of the Supreme Council of Centers of Excellence, heads of the centers, the Vice-Ministry of Health and Medical Education, Department of Health Policy Council, Health and Food Security Supreme Council, members of the Academy of Medical Sciences, the former deputy minister of Education and the Ministry of Health and Medical Education, university presidents Of type one, representatives of the Supreme Council of the Cultural Revolution, Commission of Health, Education Commission of the Parliament, Vice president of Strategic Planning and Monitoring, the heads of the medical, scientific community were gathered in 3 focus group discussion. In this stage of the drafting road map, a list of possible prospects has been made then a vision based on four criteria (compliance with style sheet of centers of excellence, compliance with upstream documents, being accessible, being motive) was drafted to COES. Then strategic goals tailored with prospective plans and interventions were draft.

All recorded interviews and FGD transcribed and coded

\section{Box 3. Upstream Documents reviewed in this study}

1. Constitution of the Islamic Republic of Iran.

2. General rules relating to higher education and research.

3. Prospects plans of Iran in 1404 and aspirational goals.

4. State general policies related to Higher Education and Research.

5. Comprehensive Scientific Map of the country.

6. Comprehensive Scientific Map of health.

7. The general policies of the Fifth Economic, Social and Cultural Development Program.

8. Provision for Fifth Economic, Social and Cultural Program.

9. Executive packages of fifth development program-related to education and research.

10. Iran's supreme leaders' statements related to education and research. (soft movement, Comprehensive scientific plan)

12. Relevant legislative decree of the Supreme Council of Cultural Revolution.

13. Rules, approval plans, Rules of procedure, related Directives in the council of Ministry of Science, Research and Technology and Ministry of Health and Medical Education. 
by two community medicine specialists.

The thematic tree was developed according to the Hovland triangle. No software was used to manage the data.

Finally, after specifying the model and operational plans, In the First year of implementation of plans in the Ministry of Health, a consensus was reached through the National Workshop and questionnaire by beneficiaries.

\section{Results}

There are 50 centers of medical excellence, according to the Ministry of Health (11). According to the documents and stakeholders' opinions, there are significant challenges for COEs which are categorized based on the Hovland triangle (12). Therefore, three themes and 8 subthemes are recognized as Table 1.

All identified themes and sub-themes are describing as below:

\section{1- Significant challenges for COEs}

Legal and political challenges: Despite the slow increase of funding for COEs, no suitable budget allocation plan has still offered to the parliamentary and presidential institutions. "Centers of Excellence are financially dependent". The budget which is granted from the Ministry of Health is very low and the process of resource allocation is not facilitated, they are limited to the use of foreign funds. "Ministry of Health sends the allocated budget to the university and rector assigns it to different centers base on his distinction." "They assume financial support of health ministry as a certain right and they used to ask for a budget". "There is a conflict in the issue of resource allocation between COESs and some departments in the universities."

The role of COEs in the fields of science, education and services is not specified in the next 5 years' development plan. There is poor coordination between activities of COEs and development programs of the country. "There is no plan for the evaluation and ranking of COEs. They do not move based on the approved and organized plan." "In most cases, even those with an organized plan do not adhere to coding standards". The main criterion to qualify COEs (educational, research and services), is "evidence of impact on the quality of life and health indicators through technology."

Suitable Conditions were not provided for the COEs to be involved in decision making and policy-making in the health sector and accept special missions to solve important problems of the country. "There is no autonomy for decision making for the centers because they are under the control of medical universities."
Currently, the development of technology and innovation is not the ultimate goal for COEs. "Their research projects are just as simple as a research center." Education in centers of excellence is not derived from researches or special innovation and technology and is similar to other current teaching teams. "Currently, centers of excellence are operating similar to universities and research centers and products of these centers are not based on the country's needs." "Centers of excellence are evaluated such as research centers and important indicators including impact on health and development of technology, are not measured. Some centers which are named as the center of excellence do not have an outstanding characteristic such as creation of new technology.

Coordinating the Secretariat of Centers of Excellence is under the supervision of the Deputy Education Minister of Health and Medical Education Ministry and "these senior department managers still believe that COEs are just educational center!" During the past 10 years, the annual Supreme Council of centers of medical excellence has been established, "which was usually held without the presence of the President of the Council."

Operational and Structural challenges: Centers of excellence are virtual infrastructure. Apart from the head of the Center of excellence, in most cases, responsibilities are not clear and the Supreme Council of the centers is the only formal structure which is distinguished from the Secretary.

Human resources of centers are not elites with best practice, and there no strategy to attract elites has been applied so far.

There are not certain relationships between centers of excellence and universities, medical research centers, the National Institute of Health Research, the private sector and NGOs. "There are challenges with attitudes of Senior of centers and faculty toward the performance of these centers." There is no proper inter-sectoral and intra-sectoral communication with excellence centers of the Ministry of Science and Technology.

Behavioral and cultural challenges: Weakness in team working is a considerable challenge in the individual level of these bodies.

Management and work in Centers of excellence are not considered as a full-time job. "Sometime dean of an excellent center is also the manager of another institution or public project."

\section{2- Road to future success}

Based on the respondent's opinion, confirmed prospects for medical COEs for the next 10 years are numerous which came in Box 4.

\begin{tabular}{lc} 
Table 1. Main themes and sub-themes & Sub-themes \\
\hline Themes & legal \& political \\
\hline 1- Significant challenges for COEs & Operational \& Structural \\
& Behavioral \& cultural \\
2- Road to future success & Vision \\
& Values \\
& Goals \\
3- Interventions for strategic plans & Physical structure \\
& Procedural structure \\
\hline
\end{tabular}


Box 4. Vision statement of centers of excellence for Medical Sciences of Iran, stakeholders' viewpoint

1) Will be in charge of science production.

2) Will be the government's main adviser in specialized fields.

3) Will be independent agencies.

4) Will take the scientific leadership in the country.

5) Will be remarkable in the Eastern Mediterranean and internationally.

6) Will be effective in policy-making of research and education on a national level through researches.

7) Centers of Excellence will reach relative financial independency and autonomy.

8) Will overcome the problems of society initiatively.

9) Will contribute directly in national and provincial policy-making and programming.

10) Some Centers of excellence would be established for specific health problems of the country.

11) The would play Important role in production of national wealth.

12) Will have scientific authority according to prospects of Iran 1404 in regional countries.

13) Will produce Global knowledge and new technology to make the superior effectiveness and efficiency throughout the world.

14) Units of knowledge in the several medical fields would be as a reference unit in Iran.

15) Will prepare conditions to innovation and creativity for scientists.

16) Will be leader for other relative research centers.

17) Ranking of centers of excellence should be identified.

18) Will be a place to operationalize theories.

19) Role of Centers of excellence in achieving the prospective of Iran in 1404 is specified.

20) Some researches of the centers would be about future studies in related field.

21) Activities of Centers of Excellence will be based on research priorities.

Stakeholders ' consensus for reaching the defined prospect of COEs consists of values, goals, and visions described in Table 2.

\section{3- Interventions for strategic plans}

There are also some i nterventions developed base on other countries' experiences and modified by the informed experts and stakeholders, which should be done to prepare

Table 2. Vision, value and goals of the plan

\begin{tabular}{|c|c|c|}
\hline Vision & Values & Goals \\
\hline $\begin{array}{l}\text { - Becoming COEs as institutions } \\
\text { with the structure and management } \\
\text { system of think tanks and technol- } \\
\text { ogy institutes that play the role of } \\
\text { reference, leader and policy advisor } \\
\text { according to the priorities. } \\
\text { - Scientific Productions, futurology } \\
\text { and innovations in selective health } \\
\text { fields } \\
\text { - Acquisition of top regional and } \\
\text { global position. } \\
\text { - Preparing conditions for providing } \\
\text { relative independency in supply re- } \\
\text { sources, attract of elites and partici- } \\
\text { pation of public sectors, Private sec- } \\
\text { tors and NGOs. } \\
\text { - Consequently, all of these are Fa- } \\
\text { cilitating the health promotion of } \\
\text { Iranian citizens at the expected level } \\
\text { for horizon } 1404 \text {. }\end{array}$ & $\begin{array}{l}\text { - Believe in just advancement } \\
\text { - Equitable development } \\
\text { - Uprooting poverty and nescience } \\
\text { - Human material or spiritual excel- } \\
\text { lence and evolution according to Is- } \\
\text { lamic patterns } \\
\text { - Comprehensive participation of } \\
\text { elites } \\
\text { - Attempting to create wealth } \\
\text { - improvement based on competition } \\
\text { and cooperation } \\
\text { - Cooperation with the same strate- } \\
\text { gies } \\
\text { - Social accountability } \\
\text { - Participatory management } \\
\text { - Localizing the science (have a use- } \\
\text { ful \& active role in the daily life of } \\
\text { people) } \\
\text { - Development of scientific culture } \\
\text { in society } \\
\text { - ethics } \\
\text { - Operation beyond the region and } \\
\text { participation of several scientific } \\
\text { systems } \\
\text { - Self-reproduction as the tip of sci- } \\
\text { ence development at the national } \\
\text { level, } \\
\text { - Commitment to the national per- } \\
\text { spective }\end{array}$ & $\begin{array}{l}\text { - } 10 \% \text { of registered patents in the region will be allo- } \\
\text { cated to Centers of excellence or each of the centers in } \\
\text { one of the specialized required fields of the country } \\
\text { and by their mission, will achieve a registered technol- } \\
\text { ogy. } \\
20 \% \text { of innovation, technology, and knowledge pro- } \\
\text { duction (ISI Medical Articles) will be allocated to } \\
\text { Centers of Excellence on a national level (regional- } \\
\text { global). } \\
\text { At least one-fifth of the medical students should be ap- } \\
\text { plied in centers of medical excellence after graduation } \\
\text { from inside or outside medical universities. } \\
\text { Exports of goods and services resulting from activities } \\
\text { of centers of excellence will be twice since the first } \\
\text { month of } 1390 \text {. } \\
\text { Each center of Excellence should perform one na- } \\
\text { tional project completely in order to achieve prospec- } \\
\text { tive goals. } \\
\text { Each center of excellence should be paramount, at } \\
\text { least in one field of health in the regional countries. } \\
\text { Each center of excellence should hold relevant educa- } \\
\text { tional courses for interested parties. } \\
\text { Outputs of centers should be } 100 \% \text { compliant with the } \\
\text { - } \text { regulations of the Centers of Excellence. } \\
\text { Each medical center of excellence will transfer one of } \\
\text { the world's premier knowledge by foreign cooperative } \\
\text { Investment. } \\
\text { Each center of excellence should achieve scientific } \\
\text { leadership in their specialized field in the country. } \\
\text { agreed by stakeholders that described in Table } 2 \text {, in } \\
\text { three groups of Obligatory, Facilitating, propagation. }\end{array}$ \\
\hline
\end{tabular}




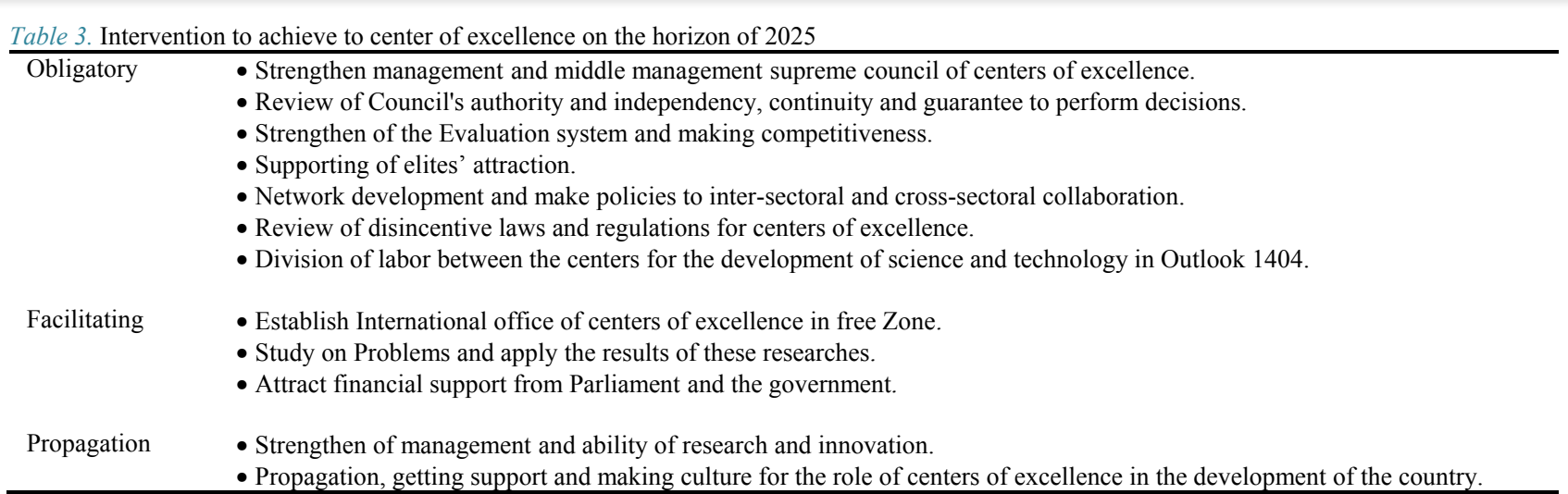

the COEs for the strategic planning application. These interventions are presents in Table 3.

For this purpose, a council consists of representatives of all deputies affiliated to the Ministry of Health (health, sanitation, education, food and medicine, research, and education) and the number of experts should constitute by the Supreme Council and Secretariat. This council should prepare a draft for necessary changes and follow them up to have quicker and more operational interaction between the Supreme Council and centers of excellence.

In order to fulfill these changes, the second senior of centers as Plenipotentiaries are in the seasonal council to supervision. On the other hand, it's suggested to have a representative from the private sector and the public. The diagram of the redesigned structure of the COEs is in Figure 1.

On the base of stakeholders' opinion, the diagram for development of the centers of excellence is as Figure 2.

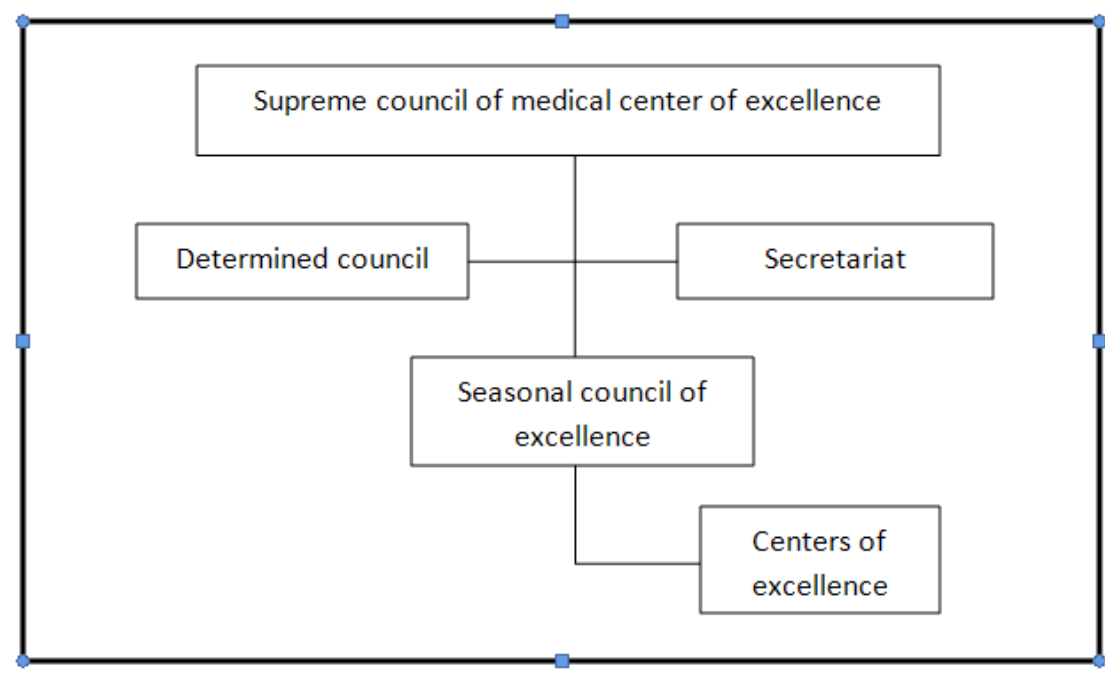

Fig. 1. Redesigned structure of centers of excellence development

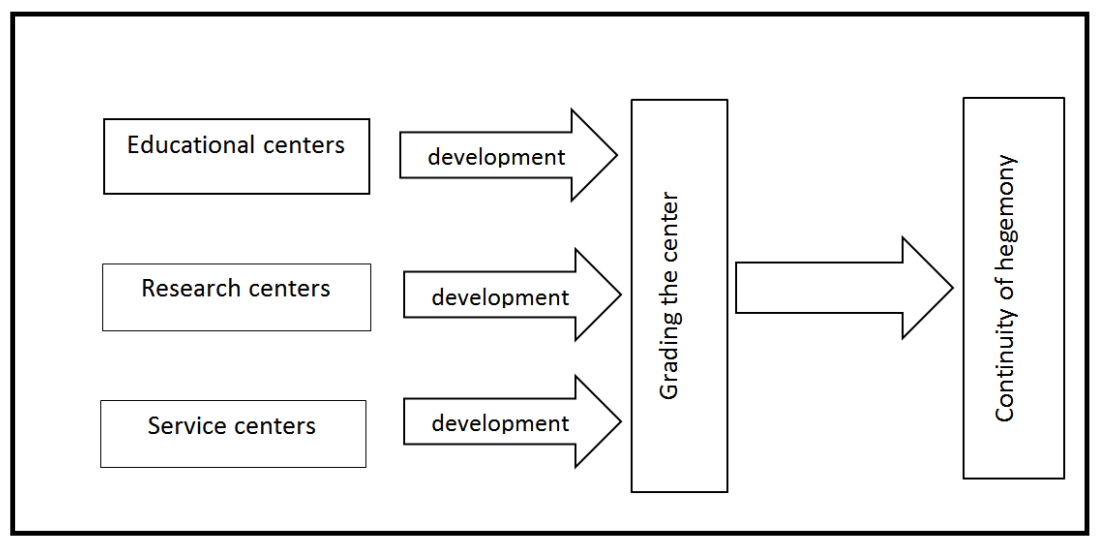

Fig. 2. Development of Centers of Excellence 


\section{Discussion}

Based on the results of this study, the five major challenges in centers of excellence, after spending ten years are, lack of common understanding of stakeholders in COEs position and roles, lack of clear professional orientation of each center for national authority, weakness of centers in the running through health system's promotion and public health improvement, weakness in elites' attraction and lack of objective goals of centers to meet the basic needs of the country. The root of most problems is in the political and legal areas.

The strategic goals which were set by the stakeholders and based on other countries interventions include Systematic policy-making of COEs in line with the long term national plans, development of activities and making competition between COEs, identifying opportunities to improve the management of COEs, and motivating toward strategic planning in each COE.

Lack of operational and developmental plans is always discussed in expertise and managerial meetings (13). There are some common findings in this study and other studies about COEs in developing countries. Insufficient supply of human resources, inefficient coordination between research and training, inadequate public funding and implementation procedures, weakness in monitoring and evaluation, low infrastructure and brain drain are all daunting challenges that COEs face in developing countries. (14-16)

Also in development and evolution of COEs there are some common factors which should be considered as what is presented in this paper: strategic partnership and networking, credibility, commitment to customers as a value, collaboration and team working, thinking globally and executing locally, systematic evaluation, commitment of legal and regulatory environment of the country are all strategies set by these studies $(5,14-16)$

Should COEs be established in a commanding way in growth and developing way of existing centers in the country, including teaching, service, and research centers? Should the centers be given budget or be funded by its own abilities and generate wealth by the management of the innovation process? These are some of the questions that this study did not provide clear answers for them; and further studies based on comparative and qualitative methodologies must provide clear answers for proper policymaking.

Publishing Roadmap and distributing it among all stakeholders is a good way to introduce and promote the road map. The main limitation of our study was the lack of informed people on this topic and the problem of accessibility to them.

\section{Conclusion}

About the road maps of centers of excellence in Academic medical centers, strategies for implementing plans were questioned, and according to suggestions, steps to approach the deploying of plan can be described. Adoption of a road plan in legal authorities like Supreme Council centers is the least activity which provides a necessary commitment for implementing this plan in national level, including confirming and adopting of rout plan by the Board of Trustees of Medical University which have a center of excellence would be effective measures to institutionalize the concept of center of excellence in regional and provincial level.

The most basic step to deploying a map is establishing a seasonal Council of centers of excellence with stakeholders to develop and implement operational plans for each center. In Each program, the contribution of the center in the realization of national programs must be determined. Establishing determined Council for each center and draft circulars and related regulations cause the increase in financial resources and facilitate the activities of COEs, and most structural and operational challenges would be resolved.

Based on a roadmap, funding support of relevant agencies would facilitated and strengthening executive staff in Secretariat of Supreme Council of Centers of Excellence will accelerate the implementation of the road map.

\section{Acknowledgement}

This plan has been fulfilled with financial support of secretariat of medical sciences center of excellence in Study and Development Center of the Ministry of Health and Medical Education and ENT and Head Neck center of Hazrat Rasool Hospital. Thereupon we appreciate all centers which patiently answered the questions:

Digestive Disease research center, Organ Transplantation Center of Shiraz University of Medical Sciences, Ophthalmology COE, Advanced e-learning COE, Tuberculosis COE, COE of Educational Technology, the research center of Endocrine Sciences and Metabolism, Cancer COE, ENT and head\& neck COE, Tehran Psychiatry Institute, Immunology COE, Hematology and Oncology researches and Bone Marrow Transplantation, Cardiovascular Research and Training Center, Hematology COE, Skin COE, COE of Nuclear Medicine research institute, science- educational excellence center of Anatomy, Toxicology and Food Chemistry COE, Science-educational Ophthalmology COE in Shahid Beheshti University, Medicinal Chemistry COE, Urology COE in Shahid Beheshti University, Children Medical COE of Tehran.

\section{Conflict of Interests}

The authors declare that they have no competing interests.

\section{References}

1. Paya A. A Reflection on the Most Important Factors of Success in the Centers of Excellence. Quart J Res Plan High Educ. 2004;9 (4):137157.

2. Action for "centers of excellence" with a European dimension. available from: http://ec.europa.eu/research/era/ pdf/centres.pdf

3. What is a center of excellence? available from: http://agileelements.words.wordpress.com/2008/10/29/what-is-acenter-of-excellence

4. Craig W, Fisher M, Garcia-Miller S, Kaylor C, Porter J, Reed LS. Generalized Criteria and Evaluation Method for Center of Excellence: A Preliminary Report. Carnegie-MellonUniv Pittsburgh Pa Software Engineering Inst; 2009 Dec.

5. Hellstrom T. Program on Innovation, Higher Education and Research for Development, Centers of Excellence as a Tool for Capacity Building. Background document. Sweden: Lund University. Available from: https://www.oecd.org/sti/Draft OECD\%20synthesis\%20report_final.pdf 
6. Farasatkhah M, Keyvani J. Science Excellence Centers; The Philosophy, Models and Functions; The 1st Seminar of Science Excellence Centers, University of Tehran, Iran. 2004. [Persian]

7. Malek-Afzali H, Foruzan AS, Momtazmanesh N, Dejman M, Fakhryaseri A. Excellence assessment model for Iranian medical centers. Teb va Tazkiyeh. 2017;19(3):9-22. [Persian]

8. Mosadeghrad AM. Factors influencing healthcare service quality. Int J Health Policy Manag. 2014 Jul;3(2):77.

9. Food safety research centre (FOSREC) mission and objective. Available from: http://www.fosrec.upm.edu.my/mission.html

10. Regulations for the formation of center of excellence approved in 1395. Available from: https://dlp.msrt.ir/file/ download/regulation/1492511437-1395.pdf

11. List of medical centers of excellence. Center for the Study and development of Medical Science. Deputy Ministry for Education. Available from: http://edc.behdasht.gov.ir/

12. Start D, Hovland I. Tools for policy impact: A handbook for researchers. London: Research and policy in development program; 2007.

13. Moore K, Birkinshaw J. Managing knowledge in global service firms: centers of excellence. Acad Manage Rev. 1998 Nov 1;12(4):81-92.

14. Guimon J. Building Research Centers of Excellence through Competitive Public Funding (Innovation Policy Platform, OECD and World Bank). Technical Report. 2013. 10.13140/RG.2.1.2555.4088.

15. Lekorwe MH. Centres of Excellence in Africa: The Contribution of CESPAM in Public Administration in the SADC Region. Innov Public Sect. 2010 Mar 1;15(1)

16. Aubert JE. Promoting Innovation in Developing Countries: A Conceptual Framework, World Bank policy research paper. 3554: pp22-23. 